\title{
Aktiv gegen Krankheitserreger
}

\author{
Keime auf Türgriffen und anderen \\ Kontaktflächen tragen zur Verbreitung \\ von Infektionskrankheiten bei. Mit \\ speziellen antimikrobiellen Beschichtungen \\ lassen sich bakterielle Krankheitserreger \\ jedoch aktiv zerstören.
}

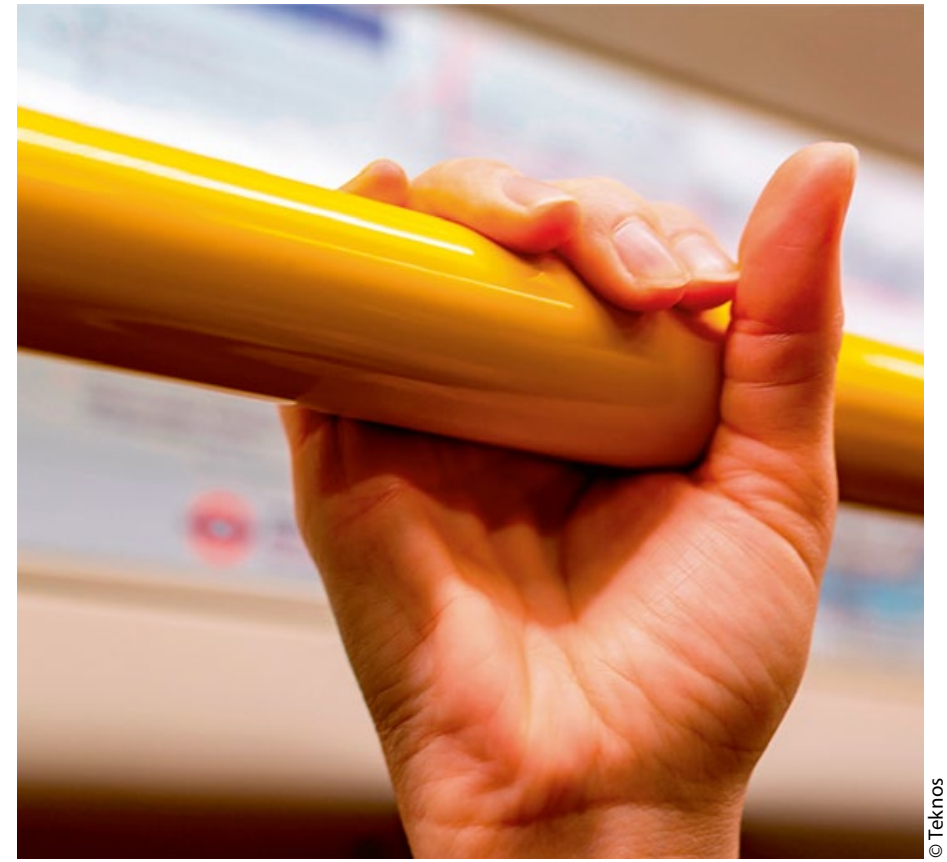

Antimikrobielle Beschichtungen helfen, die Verbreitung von bakteriellen Krankheitserregern einzudämmen.
Der Türgriff in der Arztpraxis, der Handlauf im Krankenhausflur, das Bett im Seniorenheim: Viele Infektionskrankheiten breiten sich über Kontaktflächen aus. Die Infektionsrisiken reichen von der einfachen Erkältung bis zu multiresistenten Krankenhauskeimen, mit erheblichen gesundheitlichen und wirtschaftlichen Folgen. Die Ausbreitung lässt sich maßgeblich reduzieren, wenn solche Kontaktflächen antimikrobiell ausgestattet sind.

Der Lackhersteller Teknos bietet für diesen Anwendungsbereich spezielle antimikrobielle Beschichtungen an. Grundlage ist die Ausstattung des Anstrichmittels mit Silberphosphatglas auf Basis der BioCote-Technologie. Der Wirkstoff bietet nachweislich Schutz gegen viele Arten von Mikroorganismen. Er zerstört aktiv das Wachstum und verhindert die Spaltung von Bakterien.

Der Zerstörungsprozess beginnt, sobald sich die Mikroorganismen auf der Oberfläche ansiedeln. Innerhalb einer Stunde halbiert sich die Anzahl etwa, so dass nach 24 Stunden 99,99 \% der Mikroorganismen zerstört sind. Die antimikrobielle Wirkung von Silberphosphatglas ist gemäß ISO 22196 (Messung von antibakterieller Aktivität) getestet.

Da der Wirkstoff im gesamten Anstrichmittel verteilt ist, bleiben die hygienischen Eigenschaften auch bei Abnutzung oder Kratzern erhalten. Der Einsatz von Desinfektions- und Reinigungsmitteln beein- trächtigt die antimikrobielle Wirkung der Beschichtung nicht.

\section{Pulverlacke für Kontaktflächen}

Teknos bietet mit dieser Technologie unter anderem Pulverlacke für die industrielle Beschichtung an. Der Epoxid-PolyesterPulverlack Infralit EP/PE 8235 eignet sich für die farbige Beschichtung von Stahlund Aluminiumoberflächen wie Türgriffe, Handläufe oder Armaturen. Für die farblose Beschichtung steht der Polyester-Pulverklarlack Infralit PE 8435-10 zur Verfügung, der wahlweise direkt auf Metall oder auf eine vorhandene Pulverlackschicht aufgebracht werden kann. Über die hygienischen Eigenschaften hinaus sind beide Lacke äußerst verschleißfest, korrosionsbeständig und für anspruchsvollste Anwendungen geeignet.

Eine Reihe von Studien belegen die Wirksamkeit der Beschichtungen und der Bio-
Cote-Technologie. So fielen beispielsweise in einer finnischen Schule in einem Klassenraum mit antimikrobiell beschichteten Schulmöbeln 80 Prozent weniger krankheitsbedingte Fehltage an als in einem Vergleichsraum. In einem englischen Krankenhaus wiesen antimikrobiell ausgestattete Flächen insgesamt 96 Prozent weniger Bakterien auf. Auch in Pflegeeinrichtungen, Arztpraxen, Kindergärten sowie Meeting- und Gemeinschaftsräumen können antimikrobielle Beschichtungen einen wichtigen Beitrag dazu leisten, die Verbreitung von bakteriellen Krankheitserregern einzudämmen. //

\section{Kontakt}

Teknos Deutschland GmbH, Fulda info@teknos.de www.teknos.de 